\title{
Natural Selection and Causal Productivity
}

Roberta L. Millstein

Department of Philosophy

University of California, Davis

One Shields Avenue

Davis, CA 95616 USA

$\underline{\text { RLMillstein@UCDavis.edu }}$

Forthcoming in Chao, Hsiang-Ke, Chen, Szu-Ting, and Millstein, Roberta L. (Eds.), Mechanism and Causality in Biology and Economics, History, Philosophy and Theory of the Life Sciences, Vol. 3, Springer.

\section{Abstract}

In the recent philosophical literature, two questions have arisen concerning the status of natural selection: 1) Is it a population-level phenomenon, or is it an organism-level phenomenon? 2) Is it a causal process, or is it a purely statistical summary of lower-level processes? In an earlier work (Millstein 2006), I argue that natural selection should be understood as a population-level causal process, rather than a purely statistical population-level summation of lower-level processes or as an organism-level causal process. In a 2009 essay entitled "Productivity, relevance, and natural selection," Stuart Glennan argues in reply that natural selection is produced by causal processes operating at the level of individual organisms, but that there is no causal productivity at the population level. However, there are, he claims, many populationlevel properties that are causally relevant to the dynamics of evolutionary processes. Glennan's claims rely on a causal pluralism that holds that there are two types of causes: causal production and causal relevance. Without calling into question Glennan's causal pluralism or his claims concerning the causal relevance of natural selection, I argue that natural selection does in fact exhibit causal production at the population level. It is true that natural selection does not fit with 
accounts of mechanisms that involve decomposition of wholes into parts, such as Glennan's

own. However, it does fit with causal production accounts that do not require decomposition, such as Salmon's Mark Transmission account, given the extent to which populations act as interacting "objects" in the process of natural selection.

\section{Introduction}

In the recent philosophical literature, two questions have arisen concerning the status of natural selection: is natural selection a causal process or is it a purely statistical aggregation? And second, is natural selection at the population level or at the level of individual organisms? In an earlier work, I argue that natural selection should be understood as a population-level causal process, rather than a purely statistical population-level summation of lower-level processes or as an organism-level causal process (Millstein 2006). ${ }^{1}$

In reply, Stuart Glennan (2009) argues that: 1) Natural selection is produced by causal processes operating at the level of individual organisms, but that there is no causal productivity at the population level, and 2) There are many population-level properties that are causally relevant to the dynamics of evolutionary processes. In making these replies, Glennan relies on a claim that

\footnotetext{
${ }^{1}$ In Millstein (2006), I referred to an "individual-level" causal process instead of an "organism-level" causal process. This was a somewhat unfortunate choice of terminology on my part, since, as I will discuss below, populations are themselves individuals. On the other hand, the advantage of that terminology was that it was agnostic with respect to the units of selection; the individuals in question could be genes, cells, organisms, etc. So, to be clear - in this chapter, for the sake of simplicity, I discuss only populations of organisms, with the understanding that selection can occur in populations of other entities. The more general question, then, which I won't be discussing here, is whether natural selection consists of causes that act on the individuals of any sort that constitute a population (including a population of populations) or whether natural selection consists of causes that act on the population as a whole. Also, in this chapter I will be discussing Salmon's sense of the term "causal process"; what I call a "causal process" in my 2006 paper would probably be, in Salmon's terms, part of a "causal nexus." I will return to this point briefly at the end of this chapter.
} 
there are "two types of causes,"2 causal productivity and causal relevance.

I agree with Glennan's second claim concerning the causal relevance of natural selection at the population level, but disagree with his first claim concerning the lack of causal productivity of population-level selection processes. Thus, my focus in this chapter will be on the first claim; I will argue that natural selection is produced by causal processes operating at the population level.

In what follows, I will first review Glennan's distinction between causal production and causal relevance, followed by an exegesis of his arguments for the claim that there is no causal production at the population level of natural selection. I then respond to each of his arguments. Finally, I offer positive reasons for thinking that there is casual production at the population level of natural selection processes.

\section{Glennan's causal pluralism: Causal productivity and causal relevance}

Glennan gives the following examples of causal productivity:

- The bowling ball knocked over the pin.

- The explosion made Edward deaf.

- The firing of neuron A caused the firing of neuron B.

\footnotetext{
${ }^{2}$ Others have also argued for causal pluralism, e.g., Cartwright (2004) and Hall (2004).
} 
Causal productivity, according to Glennan, is:

- a relation between events (where an event is an object doing something)

- local - spatiotemporally contiguous or connected by contiguous intermediates

- transitive - If A produces B, and B produces $\mathrm{C}$, then A produces $\mathrm{C}$.

- tied to mechanistic accounts of causation

It is the connection to mechanistic accounts of causation that most concerns us here. Glennan mentions the following mechanistic accounts as exhibiting causal production: his own (1996, 2002), Salmon's (1984), Machamer, Darden, and Craver's (2000) [hereafter MDC], and Dowe's (2000). In Glennan's terms, causally connected events require intervening mechanisms involving interacting objects (or parts or components ${ }^{3}$ ). In MDC's terms, mechanisms consist of entities engaging in activities that produce change. In Salmon's terms, causal processes "are continuous paths of objects through space-time that can interact when they intersect, producing changes in the properties of the objects that constitute those processes" (Glennan 2009, 328). Although of course Glennan has defended his own account of mechanisms, for the purposes of his arguments concerning productivity and natural selection he deems the differences in terminology and detail among the accounts of mechanisms to be not significant.

According to Glennan, causal relevance is a counterfactual relation of dependence between a fact $f$ and an event $e$. Glennan gives the following examples of causal relevance:

\footnotetext{
${ }^{3}$ See Bechtel and Abrahamsen (2005).
} 
- The fact that the Mom didn't turn off the hose was causally relevant to her basement flooding.

- The fact that the key has a certain shape is causally relevant to whether it will open the door.

- The fact that the wind is over $30 \mathrm{mph}$ increases the likelihood that a serious fire will occur.

Glennan argues that there are some cases of apparent causation that fit causal relevance but not causal production. In the "Mom" example above (a so-called "omission cause"), it is true that if Glennan's mother had turned off the hose, that her basement would not have flooded; since the counterfactual is satisfied, failure to turn off the house is causally relevant to the basement flooding. However, failure to turn off the hose is a not an event (there is no object doing something), and as a result, locality isn't satisfied, either; thus, the "Mom" example fails to exhibit causal production, according to Glennan. That is, we cannot, Glennan asserts, say that the fact that his mother didn't turn off the hose produced her flooded basement. On the other hand, Glennan maintains that there are some cases of apparent causation that fit causal production but not causal relevance, such as cases of overdetermination (Glennan 2010b). In overdetermination cases, each putative cause is sufficient to produce the effect, but neither is necessary, so that one cannot say that if the cause had not occurred, the effect would not have occurred (i.e., the counterfactual is not satisfied).

Glennan claims that full understanding of the causal basis of an event requires both the causally productive causes and the causally relevant causes and can be expressed in the form: event $c$ causes event $e$ in virtue of fact $f$. I myself am not fully convinced that there are two types of 
causes; indeed, I suspect that accounts of causal relevance and causal production reveal different aspects of the same phenomenon and that there are ways of handling the omission and overdetermination cases. However, as nothing I intend on arguing for in this chapter turns on causal monism, I will assume, for the sake of argument, that causal pluralism of the type that Glennan endorses is true. Moreover, I will mainly focus on causal production, since the question I am examining is whether natural selection exhibits causal production at the population level.

\section{Glennan's arguments against population-level causal production in natural selection}

To try to show that natural selection fails to exhibit causal production at the population level, Glennan gives an example of frequency dependent selection, which seems like it would exhibit population-level causation if any kind of selection does (Millstein 2006). He asks us to imagine a population of light and dark water bugs whose survival depends on not being seen by a predator fish. The rarer form is always fitter than the more common form because the predator fish form a stereotypic searching image associated with the more common color. Thus, when the light colored bugs are rarer, they are fitter, but once the light bugs come to predominate in the population, the dark bugs become rarer and thus fitter.

Glennan says that the water bug example shows how and why the frequency of a color form (a population-level property) is causally relevant to that form's fitness as well as to changes in the distribution of forms within the population (a population-level effect). Indeed, I've argued that natural selection in general (i.e., not just frequency dependent selection) satisfies counterfactual accounts of causation; if there were no heritable differences in physical characteristics among the 
organisms in a population (a population-level property), then there would be no differences in reproductive success. In other words, there would be nothing to be selectively favored or disfavored, as all the organisms would be of the same genotype (Millstein 2006). However, Glennan claims, we cannot strictly say that increased frequency of a form within a population produces decreased fitness of that form, because production is a relation involving objects and events, while the population is not (in this case at least) an individual object and the increase of frequency or decrease of fitness are not individual events:

The only entities here are the fish and the bugs, the only activities are the activities of individual fish and bugs, and the only interactions are when the fish eat the bugs and when the bugs make baby bugs (Glennan 2009, 331).

It is only at the level of the activities and interactions of individual bugs, he argues, that we find the mechanisms that produce new bugs.

Glennan's crucial claim here is that populations aren't objects (or in MDC's terms, entities) in this example. Glennan gives three reasons for thinking that populations aren't objects: 1) Entities need to be localized in space and time; they need to engage in particular activities at particular times and places. But, he asserts, the population in the water bug case does not have these properties; the population as a whole is spread out and does not engage in collective activities. The only activities are those of the individual organisms-swimming, evading predators, eating, etc.-and these are not activities of the population as a whole. 2) What makes a collection of parts into a single entity is that these parts have a stable structure, that the stable 
structure engages in activities as a unified entity, and that these collected parts share a common fate. But, Glennan claims, when a fish kills a water bug, it kills the whole water bug - it can't kill its legs but not its body. On the other hand, when a fish kills a water bug, it doesn't kill the whole population of water bugs. The life of one water bug is more or less independent of another. 3) One cannot say categorically that populations either are/aren't individual entities; the question of whether they are individuals only makes sense in the context of analyzing a particular causal process. He allows that an ant colony or a baboon troop may be an individual, but in this case the bugs in the pond are not.

Furthermore, according to Glennan, population-level properties don't produce change because the population is not a part of the mechanism that produces changes in genotype and phenotype frequencies. On Glennan's account of mechanisms, the parts of the mechanism have to interact with other parts in order to produce the behavior of the whole. But, he asserts, the population as a whole does not interact with other entities as a whole in order to change its genotype and phenotype frequencies.

\section{Responses to Glennan's arguments}

It is this last presupposition of Glennan's - that causal production is mechanistic production involving parts and wholes - that I will question first. I will then argue that populations do exhibit the characteristics that Glennan says are necessary to be causally productive, and thus, that populations as a whole, at a given point in time, can causally produce future states of the same population. 


\subsection{Non-decompositional causal production}

Elsewhere, Rob Skipper and I (Skipper and Millstein 2005) argue that natural selection is not a mechanism in Glennan's (or MDC's) senses. So, to some extent Glennan and I agree. However, the problem is not, as Glennan states, that "the population as a whole does not interact with other entities as a whole in order to change its genotype and phenotype frequencies" (Glennan 2009, 335). Indeed, there is at least prima facie reason to think that populations of water bugs as a whole often $d o$ interact with other entities as a whole. For example, a 1969 study of Sigara distincta (the organism on which Glennan's water bug example was based) suggests that an increase in water bugs in a particular location was due to an invasion (discussed in Macan 1976). Here "invasion" is not in the sense of an "invasive species," where a few organisms colonize a new area and reproduce rapidly; rather, it is an invasion analogous to that of an invading army. That is, the water bugs migrated as a whole, which undoubtedly changed the genotype and phenotype frequencies in the populations that they migrated from and to. (I give other examples of populations acting as a whole below). So again, the problem is not that the population as a whole does not interact with other entities as a whole in order to change its genotype and phenotype frequencies.

Rather, one of the reasons that Skipper and I were unable to construe natural selection as a mechanism in Glennan's sense is that, on his account, the interactions among the parts of a mechanism are supposed to explain the behavior of the whole. In other words, mechanistic explanations involve decomposing the whole into its parts (or, entities and activities, on the 
MDC view). However, if it were the case that a population could interact with other entities as a whole to produce changes in the very same population, this would not seem to fit the Glennan and MDC models of mechanistic explanation: The interactions of the whole would be what explain the behavior of the whole. In other words, the explanation would not be decompositional in the way that mechanistic explanations on the Glennan and MDC accounts - instances of what Skipper and I call the "new mechanistic philosophy" - seem to be.

Here it might be objected that the accounts propounded in the new mechanistic philosophy are not, in fact, decompositional. ${ }^{4}$ After all, Darden argues that "finding the mechanism for the segregation of genes did not require decomposing genes into their parts, but required finding the wholes, the chromosomes, on which the parts, the genes, ride" - in other words, finding the mechanism required going 'up' in size level rather than 'down' (Darden 2005; see also Darden 1991). Glennan, for his part, has recently given an example of an ephemeral mechanism which occurs "at" a level: the death of the French literary critic, Roland Barthes, who was struck by a laundry truck while crossing a Paris street on the way home from meeting with then-President François Mitterrand (Glennan 2010a). Other defenses of the new mechanistic philosophy, such as Bechtel and Abrahamsen (2005), Craver (2007), and Craver and Bechtel (2007) emphasize both the multi-level nature of mechanistic explanation and the importance of situating of a mechanism in its context (see especially Craver 2001 on this latter point). So, how can I claim that accounts under the new mechanistic philosophy are decompositional?

A distinction made by Salmon between etiological explanations and constitutive explanations is

\footnotetext{
${ }^{4}$ Thanks to Carl Craver, Lindley Darden, and Stuart Glennan for each pushing me on this point.
} 
useful in answering this question. Salmon states that both types of explanation are "thoroughly causal," but that etiological explanations "explain a given fact by showing how it came to be as a result of antecedent events, processes, and conditions" (1984: 269), whereas constitutive explanations show "that the fact-to-be-explained is constituted by underlying causal mechanisms"; they exhibit "the internal causal structure of the explanandum" (1984: 270). I would suggest that etiological explanations are "at" a level, whereas constitutive explanations cite lower levels by citing the parts that make up the whole (i.e., they are decompositional). According to Salmon, we can expect that most explanations will have both etiological aspects and constitutive aspects, but that there are some cases of pure etiological explanation and some cases of pure constitutive explanation. Salmon gives the explanation of "the presence of a worked bone that is thirty thousand years old in an Alaskan archaeological site" as an example of a pure case of etiological explanation, noting that "to explain this fact, it is not essential to look for the causal constituents of the bone" $(1984: 270){ }^{5}$

In general, the new mechanists seem to agree with Salmon that most explanations include both etiological and constitutive aspects; however, whereas Salmon's account emphasizes etiological explanations, the new mechanist philosophy emphasizes constitutive ones. Indeed, Craver explicitly distinguishes his project from Salmon's in exactly this way, stating, "The variety of explanation that I am interested in is constitutive (or componential) causal-mechanical explanation: the explanation of a phenomenon, such as the opening of a $\mathrm{Ca}^{2+}$ channel, by the organization of component entities and activities" (2007: 8). Similarly, Bechtel acknowledges that, "mechanistic explanations are inherently reductionistic insofar as they require specifying

\footnotetext{
${ }^{5}$ He also states, "Microphysics is invoked to ascertain the age of the bone, but not explain its presence in the site where it was discovered" (1984: 268).
} 
the parts of a mechanism and the operations the parts perform" (2011: 538). Thus, Darden's example of the mechanism for the segregation of genes seems to be the exception rather than the rule, and Glennan distinguishes ephemeral mechanisms from his primary account of systems mechanisms, which do involve the decomposition of a system into parts (Glennan 2010a, 258). ${ }^{6}$

So, to return to the point at hand: recall my claim that, contra Glennan, there seems to be at least prima facie reason to think that populations of water bugs as a whole often do interact with other entities as a whole. If it were the case that a population could interact with other entities as a whole to produce changes in the very same population, then a pure "at a level" etiological explanation would better illuminate this phenomenon than a constitutive explanation. Thus, Salmon's account, which emphasizes etiological explanations over decompositional ones - an account that Glennan accepts as providing an account of causal production, as mentioned earlier - is a more promising strategy for characterizing natural selection than the new mechanist accounts, which emphasize decompositional explanation over etiological explanation. ${ }^{7}$

To that end, let me briefly review Salmon's views. Salmon's (1984) account ${ }^{8}$ describes both causal propagation and causal production. Salmon suggests that a baseball at rest or in motion

\footnotetext{
${ }^{6}$ Illari and Williamson (2010) also seem to understand MDC mechanisms as being decompositional. Kuorikoski (2009) usefully distinguishes between mechanisms that involve decomposition and those that do not; he agrees with Skipper and Millstein (2005) that natural selection falls into the latter category. (Thanks to Till Gruene-Yanoff for the pointer to this paper).

${ }^{7}$ Skipper and Millstein (2005) offer additional reasons for thinking that the new mechanistic philosophy does not, in its current form, adequately characterize natural selection. I have focused on the issue of decomposition here in order to address the decompositional assumption behind Glennan's claim that population-level properties don't produce change because the population is not a part of the mechanism that produces changes in genotype and phenotype frequencies. I thus seek to highlight the way in which Salmon's account can provide a nondecompositional picture of causal production in natural selection.

${ }^{8}$ I focus on Salmon's Mark Transmission account rather than his later Conserved Quantity account because I believe that it is more broadly applicable to causation outside the domain of physics. Indeed, Salmon explicitly states that his 1984 account of scientific explanation is intended to cover many different disciplines, such as the behavioral sciences, the physical sciences, and the biomedical sciences (1984: 267).
} 
is a causal process because it is capable of transmitting (or propagating) a mark through time without further interactions. For example, if one makes a scuff on a baseball, the scuff simply persists on the baseball; the baseball, with its mark, propagates through time. On the other hand, changes in causal processes are produced by causal interactions, i.e., intersections of processes where changes in the characteristics of the processes occur at and persist beyond the space-time point of intersection. For example, the interaction of a moving baseball (a causal process) and a window (another causal process) can produce a change in both the window and the baseball, namely, the breaking of the widow and a change in the trajectory of the baseball. Note that there is no decomposition here; neither the baseball nor the window need to be broken down into parts in order to explain the interaction between the two causal processes or the production of change. Indeed, the mass of the entire ball is one factor (aside from velocity, wind resistance, etc.) in the window's breaking exactly the way it did. ${ }^{9}$

Although Salmon distinguishes between causal propagation and causal production, it seems to me that causal propagation can be construed as a type of causal production, or at least, construed as causal production in Glennan's sense. Recall that, according to Glennan, causal production is: 1) a relation between events 2) local, and 3) transitive. Propagation very clearly satisfies all three of these criteria. The events in question are the ball at one point in space-time and the ball at a subsequent point in space-time; these events are contiguous in time and space and, given a third event in space-time, transitive. I will refer to my claim that causal propagation is a type of causal production later in the chapter.

\footnotetext{
${ }^{9}$ Similarly, Salmon notes that when two moving pool balls intersect in space-time, energy and momentum are transferred, altering the states of motion of both balls; thus, the intersection is a causal interaction in which the change in each process can be said to be produced by the other process (1984: 169-170).
} 
Now suppose that, like a baseball, a population is capable of transmitting a mark; it would then be considered a causal process on Salmon's account, capable of propagating causal influence through space and time. If so, the population could interact with other causal processes, producing a change in the characteristics of those processes at the same time that the other processes produced a change in the characteristics of the population. Then it would seem as though a population could be causally productive of its own changes without citing the activities of the organisms that compose it. But for this to be the case, a population would need to be an object (categorically, and not just in certain situations), so let us turn to that question.

\subsection{Populations as individuals}

Elsewhere (Millstein 2009, 2010), I argue that populations are individuals (“objects”), using the Ghiselin-Hull individuality thesis as my inspiration (Ghiselin 1974, 1997; Hull 1976, 1978, 1980). Briefly, my argument is that populations are composed of individual organisms, just as

organisms are composed of individual cells; a population is a particular thing - not a class, since it exists in space and time, and not merely a set, since it is integrated via the survival and reproductive interactions of its constituent members with members having a shared fate (albeit less so than organisms); a population has a beginning in time (e.g., migration of organisms away from a population) and an ending in time (e.g., death of the last organism in a population); a population does change over time, but so do organisms; and a population is continuous in time 
via the causal interactions that occur over time..$^{10}$

The main aspect that Glennan seems to miss here is the extent to which populations are integrated. Recall his claim that "when a fish kills a water bug, it doesn't kill the whole population of water bugs. The life of one water bug is more or less independent of another" (2009, 333). But it isn't true that the life of one water bug is more or less independent of another. If a fish kills a water bug, then there are more resources (e.g., food, mates) available for the other water bugs. Conversely, a water bug who is adept at obtaining food and mates affects other bugs because those resources are no longer available to them. Indeed, on my view, populations are characterized by their survival and reproductive interactions, with the boundaries of the population as the largest grouping where the rates of interaction are much higher within the grouping than outside. Thus, it seems prima facie as though populations can be causally productive in the process of natural selection.

\subsection{Potential worries}

But further worries remain. Glennan implies that for populations to be causally productive, they would need to (1) be localized in space and time, (2) have a stable structure, (3) engage in activities as a unified entity in particular times and places, (4) be individuals in the natural

\footnotetext{
${ }^{10}$ Here one might worry about circularity if individuals ("objects") are characterized in terms of interactions, if causal processes are objects persisting and changing through space-time, and if interactions are intersections of causal processes. However, Salmon (1994) clarifies that interactions are not to be defined in terms of causal processes, only in terms of processes more generally, where "[a] process is something that displays consistency of characteristics" $(1994,299)$. Causal processes are then characterized by their ability to transmit marks, where a mark is a type of interaction - "an alteration to a characteristic that occurs in a single local intersection" (Salmon 1994, 299). An object persisting or changing through space-time is one example of a causal process; however, a carrier wave is another.
} 
selection process, and (5) have parts that share a common fate.. I'll take up each of these criteria one at a time, and show that populations do, contra Glennan, in fact meet them.

With respect to localization in space and time, Glennan worries that in the water bug scenario, "the population as a whole is spread out," which is certainly the case. But there are spaces between the cells that compose an organism. So, the issue is not space per se, but rather, whether the parts are close enough in space and time so that they can be interacted with as a whole. In Glennan's natural selection example, the predator fish is able to form a stereotypic image of the water bug with the more common color, suggesting that the predator fish is able to perceive the population (or at least a significant subset of it) as a whole. Thus, the population is sufficiently localized in space and time to engage in causal production.

The second worry is that populations aren't sufficiently stable in the face of interventions to interact as a whole, and it is true that populations are not entirely stable. Even without changes in the environment ("interventions"), organisms may be born (increasing the size of the population) or die (decreasing the size of the populations). Immigration or emigration may also change the size of the population. However, consider fire (a type of "intervention") - a process that would destabilize many otherwise stable entities. Even if many of the organisms of a population were to die in a large fire, the population would generally still retain many of the characteristics that it had before the fire: it would be composed of members of the same species that it was composed of before the fire, some of the same organisms would remain, and some of the genetic and trait variations would remain. Thus, populations seem sufficiently stable to engage in causal production. 
The third worry is that populations don't seem to engage in activities as a unified entity in particular places and times. Here, it is not entirely clear what counts as an activity, and if Glennan means to fully take on the MDC notion of activity (which is itself not entirely clear). However, here are some candidate activities that populations can engage in as a whole: invading (as discussed above), changing other populations (e.g., as with predator/prey interactions), splitting, going extinct, speciating, and changing their environments in a way that facilitates colonization by populations of other species. Indeed, if it turns out that that these do not count as activities, so much the worse for the requirement that entities engage in activities. They all involve interactions (the term used in Glennan's own account of mechanisms) between populations and other entities, including interactions between populations and entities in the populations' environments.

Glennan does acknowledge that populations sometimes act as individuals, e.g., in migration processes. However, he says, "With respect to selection processes, the question of whether or not populations or sub-populations should be treated as individual entities depends upon whether or not group selection is at work" (Glennan 2009, 333). More generally, “The question of whether they are individuals only makes sense in the context of analyzing a particular causal process" (Glennan 2009, 333). So, this raises a fourth worry, whether populations are individuals in the natural selection process specifically.

However, it seems to me that the population is acting as an individual with respect to the selection example that Glennan describes, even in the absence of group selection. Again, recall 
that the fish form an image associated with the more common color. This in itself is evidence that there is an interaction between the fish and the population as a whole - the fish forms an impression of the population as a whole, and the image is a result of the interaction. Of course, when a predator fish kills a water bug, there is an interaction between an individual predator and an individual bug. But that single interaction does not constitute a natural selection process, just as the interaction of your fingers with a keyboard does not constitute the creation of a document (which involves your interaction with the whole computer). Or, to invoke an analogy for selection processes more generally, a single particle of flour falling through the hole of a sifter does not constitute sifting. One sifts not a single particle of flour, but rather a "population" of flour particles, with particles jostling against each other, some falling through and some remaining in the sifter. Similarly, selection occurs with respect to the whole population. Types are only selectively favored or disfavored as compared to other types in the population; a type that might appear reproductively successful when considered individually is actually unsuccessful in the selection process if other types outreproduce it (Millstein 2006). Thus, for selection in general, the population acts as an individual.

Finally, there is the worry that populations do not have parts that share a common fate. However, the fact that the organisms (the "parts") of a population are engaging in survival and reproductive interactions implies that they do have a shared fate, at least to some extent. For example, consider a new advantageous variation introduced into a population. If there is interbreeding among the organisms (one kind of reproductive interaction), then that variation may spread in the population, enhancing the survival of the population as a whole. Indeed, there 
are many kinds of interactions among the members of the population. ${ }^{11}$ Survival interactions include direct physical combat; competition for limited food, sunlight, or shelter resources; and cooperation, whereas reproductive interactions include mating successfully or unsuccessfully and offspring rearing. Lots of interactions imply that the organisms will share a common fate to a high degree.

To summarize, I've argued that populations, to a sufficient extent, are categorically individuals (objects) and are localized in space and time, that they do have a stable structure, that they engage in activities as a unified entity, and that the members of a population share a common fate. Thus, populations are not excluded from being causally productive on that basis. But to make the positive case for populations as causally productive, I return to Salmon's account of causal propagation, causal production, and the baseball example, which I use as an analogy.

\section{Populations can be causally productive}

First, like a baseball, a population is capable of transmitting a mark. For example, if an organism in the population is born or killed, that "mark" persists in future states of the population. Michael Strevens (personal communication) raises the worry that if an organism disappearing from the population counts as a mark, then Salmon's criterion will collapse. According to Strevens, Salmon wants to say, for example, that a shadow traveling across a wall is not a causal process because "marks" made on the shadow at one point (e.g., by a blemish on

\footnotetext{
${ }^{11}$ The interactions within (or among) the members of a population are to be distinguished from the interactions between the population as a whole and other entities. It is the occurrence of the former interactions that binds the population together as a whole and thus makes possible the latter kinds of interactions.
} 
the wall) do not persist to the next point - but the effect on a population of killing a member seems very much like that (at one moment there, at the next moment not). Here I would respond that, on my account, an organism is a member of a population in virtue of the fact that it is interacting with other members of the population. So, if a new organism is born, it will affect other organisms: eat their food, offer them some food, mate with them, refuse to mate with them, etc. The population is changed because of that new organism. So, when that organism later dies, the rest of population is similarly affected - perhaps a small amount, but an effect nonetheless. And since most organisms are more than just ephemeral shadows (let's suppose most of them live more or less the average for the species), I think their appearance and disappearance is different than the appearance and disappearance of a shadow. The organisms persist, and thus, so does the mark on the population. That being said, there are probably more obvious sorts of marks, such as a disease that quickly spreads through a population, and, of course, all that really needs to be shown for a population to be a causal process on Salmon's account is that a population is capable of transmitting a mark. My point in choosing birth and death as examples of marks is that mark transmission is not only possible for a population, it's commonplace.

Second, like a baseball at rest or in motion, the state of the population (the entity) at one point in space-time can propagate its influence to another point in space-time simply by persisting or even while changing (e.g., moving). The genotype and phenotype frequencies of a population at one point in time probabilistically ${ }^{12}$ propagate the genotype and phenotype frequencies to future points in time. This propagation is reflected in transition probability models, equations that describe the probability of various possible future states, given the current state of a population.

\footnotetext{
${ }^{12}$ Salmon intends his account to include probabilistic processes; see, e.g., his 1984, p. 268.
} 
Future states of the population are partially the result of, and are constrained by, present states. As I suggested above, this propagation itself is a type of causal production, albeit different than the type of causal production that occurs as the result of an interaction.

Third, like a baseball that hits a window, the population can produce changes in other causal processes through causal interactions and be changed in turn. As Skipper and Millstein (2005, 345) suggest, "To capture natural selection as a mechanism, an account of productive continuity is required that captures the ways in which relevant property differences among a population of entities entering into causal interactions with their environment is productive of change in that population." To return to Glennan's example, recall that each predator fish is forming a stereotypic searching image representing the most common water bug color in the population; this is an interaction between the fish and the water bug population. Thus, we can say that a population of water bugs, with dark forms rarer, repeatedly interacts with predator fish to probabilistically produce relative increases in the darker form as a result of preferential predation (discriminate sampling) of the lighter forms. In this way, natural selection can, contra Glennan, exhibit causal production at the population level.

Or consider one of the cases discussed in Skipper and Millstein (2005) where frequencydependent selection is not involved. Suppose there exists a population of finches that vary in their beak length, a heritable trait, with the varying beak lengths conferring variable abilities to obtain seeds for food. The population of finches repeatedly interacts with the seeds in the environment, so that some finches are favored over others based on the differences among the finches, producing future changes in distributions of types in the population. In other words, the 
environment (in the form of seeds) discriminates among the members of the finch population;

this interaction between population and environment produces changes in both the population and the environment (analogous to an interaction between flour and a sifter). Again, it is of course true that a particular finch can also interact with a particular seed, but that interaction neither constitutes selection nor prevents an interaction from occurring at the population level. This case illustrates how even in non-frequency-dependent situations natural selection exhibits causal production at the population level.

These three points taken together clarify the way in which populations can be seen as causally productive via Salmon's Mark Transmission account. However, I must make a few caveats. I am not endorsing Salmon's account over other accounts of causation or mechanisms; other accounts may be needed to supplement Salmon's account or may handle other sorts of cases better. ${ }^{13}$ Moreover, I do not think this discussion of Salmon's account captures everything there is to be said about natural selection as a population-level causal process (or, to be consistent with Salmon's terminology, perhaps I should say "natural selection as a population-level causal nexus," since there are many interactions between populations and their environments and

\footnotetext{
${ }^{13}$ One worry that has been raised by a number of recent authors, including Glennan (Glennan 2009; see also Hitchcock 1995 and Craver 2007) is that Salmon's account fails to pinpoint which of the causal processes that produce an effect are explanatorily relevant. In one version of an example which purports to illustrate the problem, Ms. Slims chalks her cue stick with blue chalk and deftly hits the cue ball, which hits the eight ball, which proceeds to the corner pocket. The claim seems to be that, while the blue "mark" has been transmitted (perhaps even to the eight ball), it is not explanatorily relevant to the effect. However, I think we need to be clear on what the effect is; if we are talking about a token chain of events (and not a type of chain of events), then the effect that occurred is that an eight ball with a blue mark dropped into a corner pocket. And the blue mark is explanatorily relevant to that token event, just as the momentum of the cue ball is. We still might be worried that Salmon wanted his account to be able to give an explanation for the event-type "ball in the corner pocket," and that the blue mark is not relevant to that. Here, I think three possible responses are open. One is that explanatory relevance and causal relevance come apart; the blue mark is always causally relevant, but it simply isn't explanatorily relevant to the event-type. Second is to insist that in explaining why an eight ball with a blue mark has gone into the corner pocket, we've already explained why the eight ball has gone into the corner pocket. Third is to give up on using Salmon's account to explain event-types, and only use it to explain event-tokens. (Thanks to Christopher Hitchcock for helpful discussion).
} 
populations and other organisms); for example, I haven't said anything about the way in which natural selection can be distinguished from other, similar causal processes, such as sexual selection and artificial selection. But I do think that Salmon's views on causal propagation and causal production can capture something important about the role of populations in natural selection, namely, something about the ways in which populations propagate their influence through space and time, and something about the ways in which their interactions with various other entities in their environment produce changes in populations.

\section{Conclusions}

My main goal in this chapter has been to respond to Glennan; Glennan argues that entities like populations can only give rise to causally relevant causes in the process of natural selection, but as I have sought to show, populations can be causally productive, too, both through causal propagation and causal interactions. I was initially motivated to respond to Glennan because it seemed to me that, if correct, his claims would imply that the merely causally relevant causes occurring at the population level were somehow "lesser" than the more robust causally productive causes at the level of individual organisms. These thoughts probably have more to do with my views about causation than Glennan's, although I am apparently not alone in this way of thinking; as Jaegwon Kim suggests, “causal production, which respects the locality/contiguity condition" involves "real connectedness between cause and effect" (2007: 236; emphasis in

original). Furthermore, Glennan claims that full understanding of the causal basis of an event requires both the causally productive causes and the causally relevant causes even though he believes that at the population level of natural selection there can be causal relevance without 
causal production. This seems to leave bare causal relevance at the population level a bit freefloating and weird. Finally, although in this chapter I have not sought to question the claim that there are two kinds of causes, I find it somewhat troubling. For all of these reasons, it seemed to me that he was mounting a serious challenge to my claim that natural selection is a populationlevel causal process (Millstein 2006): that those population-level causes were "lesser," or "free floating and weird" or part of a distinction that was not fully coherent and thus perhaps ephemeral. So, responding to Glennan here is, in part, a defense of my earlier work.

However, I hope to have made some other, more general points along the way. One is that while I find the new mechanists' approach appealing for many areas of biology (such as molecular biology and neuroscience), I do not think it illuminates all cases. This echoes a claim of Skipper and Millstein (2005), but here I go beyond that negative claim to show how Salmon's Mark Transmission account can be more helpful in understanding other sorts of biological phenomena, such as natural selection. Salmon eventually abandoned his Mark Transmission account because he felt it relied too much on counterfactuals; however, for people like me who do not find counterfactuals ontologically objectionable (and anyone who defends a causal dependence view of causality cannot find counterfactuals ontologically objectionable), there is much insight to be gained by analyzing cases in terms of Salmon's account. In part, this is because (as I argued above) phenomena such as natural selection are better suited to non-decompositional, etiological accounts, rather than the constitutive decompositional accounts that the new mechanists emphasize. Sometimes, all we need is to cite causation "at" a level. However, I also think that concepts such as "causal processes," "causal propagation," and "causal interaction" are rich and powerful tools. I recommend Salmon's Mark Transmission account as an alternative to the new 
mechanists' approach - again, not as a replacement but as a supplement. I expect that other areas of biology and science more generally might be fruitfully examined through the lens of Mark Transmission. Whether Salmon's account should itself be considered a type of mechanist approach is a matter for another time, and I do not think anything I've said here turns on that question.

Finally, I think it is important that we understand what sort of entities can enter into causal relations, and in what ways. I think we have certain human-centered biases about what entities count as individuals, and these biases can lead us to mistaken conclusions about causality. If populations can be causally productive, perhaps other, similar entities can as well: communities, ecosystems, etc. Organisms are not a privileged level of organization.

\section{Acknowledgements}

Thanks to Carl Craver, Lindley Darden, and Stuart Glennan for much relevant and productive discussion about causation and mechanisms. Thanks also to the Griesemer/Millstein Lab, my Winter 2011 Philosophy of Science seminar, and attendees of the Taiwan Conference on the Philosophy of Biology and Economics for helpful comments and questions, and to Joyce Havstad and Michael Strevens for helpful comments on my draft. Finally, thanks to Carl Craver for an excellent set of referee comments.

\section{References}


Bechtel, William. 2011. Mechanism and Biological Explanation. Philosophy of Science 78:533-557.

Bechtel, William, and Adele Abrahamsen. 2005. Explanation: A Mechanist Alternative. Studies in History and Philosophy of Biological and Biomedical Sciences 36:421-441.

Cartwright, Nancy. 2004. Causation: One Word, Many Things. Philosophy and Phenomenological Research 71:805-819.

Craver, Carl F. 2001. Role Functions, Mechanisms, and Hierarchy. Philosophy of Science 68:53-74.

Craver, Carl F. 2007. Explaining the Brain. Oxford: Oxford University Press.

Craver, Carl F., and William Bechtel. 2007. Top-down Causation Without Top-down Causes. Biology and Philosophy 22:547-563.

Darden, Lindley. 1991. Theory Change in Science: Strategies from Mendelian Genetics. Oxford: Oxford University Press.

Darden, Lindley. 2005. Relations Among Fields: Mendelian, Cytological and Molecular Mechanisms. Studies in History and Philosophy of Biological and Biomedical Sciences 36 (2):349-371.

Dowe, Phil. 2000. Physical Causation. Cambridge: Cambridge University Press.

Ghiselin, Michael T. 1974. A Radical Solution to the Species Problem. Systematic Zoology 23 (4):536544.

Ghiselin, Michael T. 1997. Metaphysics and the Origin of Species. Albany: SUNY Press.

Glennan, Stuart. 1996. Mechanisms and the Nature of Causation. Erkenntnis 44:49-71.

Glennan, Stuart. 2002. Rethinking Mechanistic Explanation. Philosophy of Science 69:S342-S353.

Glennan, Stuart. 2009. Productivity, Relevance, and Natural Selection. Biology and Philosophy 24:325339.

Glennan, Stuart. 2010a. Ephemeral Mechanisms and Historical Explanation. Erkenntnis 72:251-266.

Glennan, Stuart. 2010b. Mechanisms, Causes, and the Layered Model of the World. Philosophy and 
Phenomenological Research LXXXI (2):362-381.

Hall, Ned. 2004. Two Concepts of Causation. In Causation and Counterfactuals, eds. John Collins, Ned Hall, and L. A. Paul, 225-276. Cambridge, MA: The MIT Press.

Hitchcock, Christopher Read. 1995. Salmon on Explanatory Relevance. Philosophy of Science 62 (2):304-320.

Hull, David L. 1976. Are Species Really Individuals? Systematic Zoology 25:174-191.

Hull, David L. 1978. A Matter of Individuality. Philosophy of Science 45:335-360.

Hull, David L. 1980. Individuality and Selection. Annual Review of Ecology and Systematics 11:311332.

Illari, Phyllis McKay, and Jon Williamson. 2010. Function and organization: comparing the mechanisms of protein synthesis and natural selection. Studies in History and Philosophy of Biological and Biomedical Sciences 41:279-291.

Kim, Jaegwon. 2007. Causation and Mental Causation. In Contemporary Debates in Philosophy of Mind, eds. Brian McLaughlin, and Jonathan Cohen, 227-242. New York: Wiley-Blackwell.

Kuorikoski, Jaakko. 2009. Two Concepts of Mechanism: Componential Causal System and Abstract Form of Interaction. International Studies in the Philosophy of Science 23 (2):143-160.

Macan, T. T. . 1976. A Twenty-One Year Study of the Water-Bugs in a Moorland Fishpond. Journal of Animal Ecology 45 (3):913-922.

Machamer, Peter, Lindley Darden, and Carl F. Craver. 2000. Thinking About Mechanisms. Philosophy of Science 67:1-25.

Millstein, Roberta L. 2006. Natural Selection as a Population-Level Causal Process. The British Journal for the Philosophy of Science 57 (4):627-653.

Millstein, Roberta L. 2009. Populations as Individuals. Biological Theory 4 (3). 
Millstein, Roberta L. 2010. The Concepts of Population and Metapopulation in Evolutionary Biology and Ecology. In Evolution Since Darwin: The First 150 Years, eds. M. A. Bell, D. J. Futuyma, W. F. Eanes, and J. S. Levinton, 61-86. Sunderland, MA: Sinauer.

Salmon, Wesley. 1984. Scientific Explanation and the Causal Structure of the World. Princeton, NJ: Princeton University Press.

Salmon, Wesley. 1994. Causality without Counterfactuals. Philosophy of Science 61:297-312.

Skipper, Robert A., and Roberta L. Millstein. 2005. Thinking about Evolutionary Mechanisms: Natural Selection. Studies in History and Philosophy of Biological and Biomedical Sciences 36 (2):327347. 